\title{
Fracture of alumina particulate reinforced aluminium alloy matrix composites
}

\author{
S V KAMAT* and J P HIRTH ${ }^{\dagger}$ \\ Defence Metallurgical Research Laboratory, P. O. Kanchanbagh, Hyderabad 500258 , \\ India \\ †Mechanical and Materials Engineering Department, Washington State University, \\ Pullman; WA 99164, USA
}

MS received 27 May 1991

\begin{abstract}
Fracture toughness tests were performed on two aluminium alloy matrices, $2014-0$ and $2024-0$ reinforced with alumina particulates of different volume fractions and particulate sizes so as to investigate the fracture mechanisms operative in such composites and to determine how microstructural parameters such as volume fraction, particulate size and interparticle spacing affect the fracture toughness. The results indicate that fracture occurred by a locally ductile mechanism. The fracture toughness increased with increasing particle spacing provided that the particle size was less than a limiting value, above which unstable crack growth occurred and the toughness lowered.
\end{abstract}

Keywords. Fracture mechanism; microstructural parameters; fracture toughness; aluminium alloy matrix composite.

\section{Introduction}

The development of metal-matrix composites has been catalysed by the need for materials with high specific strengths and stiffness, wear resistance, dimensional stability and thermal conductivity. The current focus is on particulate-reinforced metal-matrix composites since they are less expensive, easier to process and are more isotropic in their properties as compared to the continuous fibre-reinforced composites. Applications for such composites are envisioned primarily in the aerospace, automotive and sporting equipment market sectors.

Currently moderate knowledge exists on the mechanical properties of particulatereinforced metal-matrix composites but not much is known about their fracture behaviour. A detailed investigation of the fracture properties is essential for assessing the flaw tolerance and load-bearing ability of such materials before using them in structural applications. The objectives of this paper were to shed light on the fracture mechanisms operative in such composites and to determine how the microstructural parameters, such as volume fraction $\left(V_{f}\right)$, particulate size $(D)$ and interparticle spacing $(\lambda)$ influence the fracture toughness. Two aluminium alloy matrices, $2014-0$ and $2024-0$, reinforced with alumina particulates of different volume fractions and particulate sizes were chosen for this purpose.

\section{Experimental}

Composites comprising alumina particulates in either 2014-0 or 2024-0 aluminium alloy matrices were prepared using a slurry casting technique, the details of which

*For correspondence. 
were reported by Hosking et al (1982). The nominal composition of the matrices in wt \% was $2014: 4.4 \mathrm{Cu}, 0.8 \mathrm{Si}, 0.8 \mathrm{Mn}, 0.4 \mathrm{Mg}$, balance $\mathrm{Al} ; 2024: 4.5 \mathrm{Cu}, 1.5 \mathrm{Mg}$, $0.6 \mathrm{Mn}$, balance Al. The composites had a nominally homogeneous distribution of alumina particulates with the surrounding matrix being void-free. The composites also had excellent bonding between the alumina particulates and the aluminium matrices. The bonding was postulated to be associated with the formation of $\mathrm{MgAl}_{2} \mathrm{O}_{4}$ and $\mathrm{CuAl}_{2} \mathrm{O}_{4}$ spinel particles at the interface (Hosking et al 1982). Interface interactions between alumina and aluminium alloy matrices during the fabrication of composites by slurry casting have earlier been investigated and discussed (Levy et al 1978; Quigley et al 1982).

Mode I fracture toughness of the composites was evaluated. The test specimen design shown in figure 1 is based on the standard compact tension specimen design recommended by ASTM E-399 (ASTM 1987). The specimens were tested on a MTS 810 servohydraulic testing machine at a constant cross-head speed of $10 \mu \mathrm{m} / \mathrm{s}$ and the load and crack opening displacements recorded. All the broken compact tension specimens were examined under SEM to identify the fracture mechanism. Some fractured specimens were sectioned in a plane perpendicular to the crack plane to examine the material just underneath the fracture surface and the extent of subsurface microcracking. The measured properties of the composites are listed in table 1.

\section{Results and discussion}

\subsection{Fracture mechanisms}

The identification of a fracture mechanism in particulate-reinforced composites is

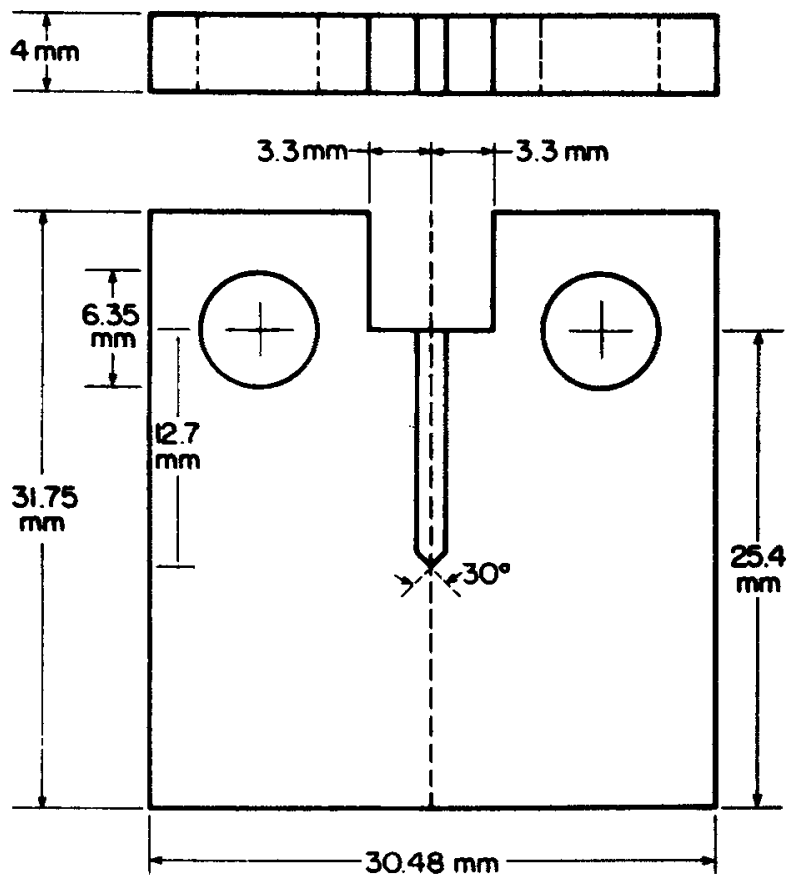

Figure 1. Mode I compact tension specimen design for fracture toughness testing. 
Table 1. Microstructural parameters, tensile data and fracture toughness for alumina particulate reinforced aluminium alloy-matrix composites.

\begin{tabular}{lccccccc}
\hline Matrix & $\begin{array}{c}D \\
(\mu \mathrm{m})\end{array}$ & $V_{f}$ & $\begin{array}{c}\lambda \\
(\mu \mathrm{m})\end{array}$ & $\begin{array}{c}\sigma_{y} \\
(\mathrm{MPa})\end{array}$ & $\begin{array}{c}\sigma_{u} \\
(\mathrm{MPa})\end{array}$ & $\varepsilon_{f}$ & $\begin{array}{c}K_{\mathrm{IC}} \\
(\mathrm{MPa} \sqrt{\mathrm{m}})\end{array}$ \\
\hline 2014 & - & - & - & 97 & 185 & $0 \cdot 18$ & 35 \\
2014 & 5 & $0 \cdot 02$ & $25 \cdot 58$ & 128 & 265 & $0 \cdot 10$ & $14 \cdot 6$ \\
2014 & 5 & $0 \cdot 05$ & $16 \cdot 18$ & 137 & 280 & $0 \cdot 073$ & $13 \cdot 5$ \\
2014 & 15 & $0 \cdot 05$ & $48 \cdot 54$ & 118 & 237 & $0 \cdot 004$ & $13 \cdot 9$ \\
2024 & - & - & - & 75 & 185 & $0 \cdot 21$ & 40 \\
2024 & 5 & $0 \cdot 02$ & $25 \cdot 58$ & 100 & 227 & $0 \cdot 12$ & 16.6 \\
2024 & 5 & $0 \cdot 05$ & $16 \cdot 18$ & 107 & 240 & $0 \cdot 090$ & $15 \cdot 8$ \\
2024 & 5 & $0 \cdot 20$ & $8 \cdot 09$ & 114 & 252 & $0 \cdot 043$ & $12 \cdot 2$ \\
2024 & 50 & $0 \cdot 20$ & 80.90 & 92 & 194 & $0 \cdot 025$ & $13 \cdot 2$ \\
\hline
\end{tabular}

essential for the correlation of microstructure and properties for such materials. However, the complexity of these materials has made the identification of an unique fracture mechanism for such materials extremely difficult. Several investigators (Crowe and Gray 1984; Nutt and Duvà 1986; You et al 1987) have attempted in recent years to shed light on the detailed fracture mechanism in such composites. The general consensus appears to be that although these composites exhibit limited macroscopic ductility, fracture occurs by a ductile mechanism of void initiation, growth and linkage. A similar behaviour was observed for alumina particulatereinforced aluminium alloy-matrix composites except for composites with very large particulate sizes. A few representative fractographs are shown in figure 2. The fracture surfaces essentially consisted of a bimodal distribution of flat dimples of the order of 5-20 $\mu \mathrm{m}$ in size, associated with the alumina particles and small dimples, less than $1 \mu \mathrm{m}$ in size associated with the ductile failure of the aluminium alloy matrix. These observations are analogous to the observations of You et al (1987). In most cases the large dimples contained alumina particles and were of the same approximate size as the particles responsible for their formation. The observation of stereo pairs revealed the dimples to be shallow, which is consistent with the low plasticity levels exhibited by these composites. Also the observation of stereo pairs at high magnifications showed smooth planar particle surfaces for a majority of the particles which indicate that particle fracture and not decohesion was responsible for void formation. A few secondary branches of the crack were observed on the fracture surface for all the composites and were confirmed by cross-sectional views of the region adjacent to the fracture surface. Based on the fractographic observations the sequence of events which lead to fracture in such composites can be visualized as follows: Plastic deformation occurs around the crack tip due to the high stress concentration. The initial high dislocation density in the matrix caused by thermal mismatch during processing, makes the matrix incapable of sustaining much more plastic deformation at the crack tip prior to fracture. Voids nucleate at the alumina particles mostly by cracking of the particles. These primary voids do not undergo much growth as evidenced by their being essentially of the same size as the particles responsible for their formation, before they are linked up by smaller $(<1 \mu \mathrm{m})$ voids (most likely associated with the ductile fracture of the matrix) resulting in fracture. For the case of composites with large particulates, a particle in the deformed region cracks resulting in the formation of a microcrack. If the local energy release rate associated with the microcrack formation exceeds the local matrix toughness, the 

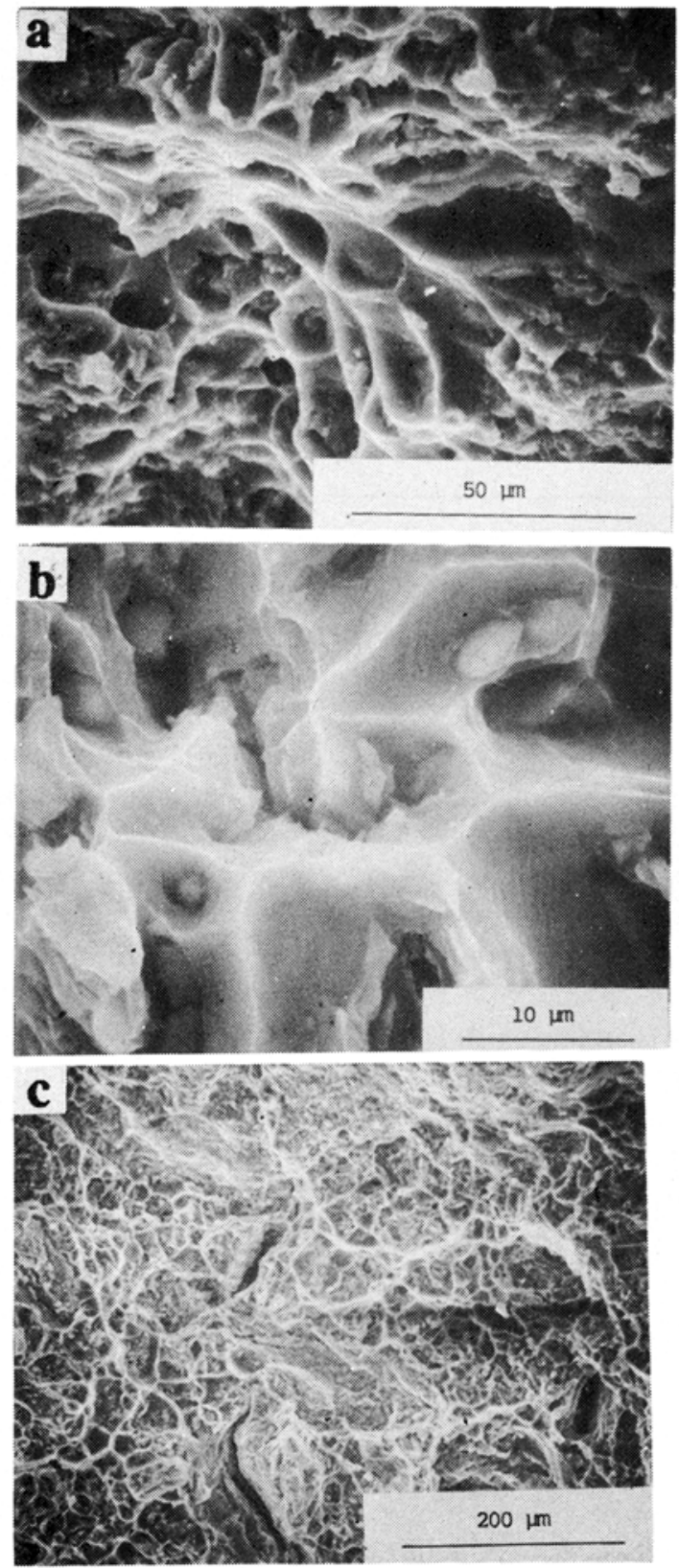

Figure 2. SEM fractographs showing locally ductile fracture: (a) bimodal dimple distribution. (b) equiaxed shallow dimples nearly the same size as alumina particles and (c) secondary branching of crack visible on the fracture surface.

microcrack links up with the main crack triggering unstable crack extension. If one can minimize the inherent flaws in the alumina particles caused during processing, one can delay the fracture and hence improve ductility and fracture toughness.

The above mechanisms imply that particulate size, volume fraction, spacing and the matrix all play a significant role in the fracture process. Improvements in 
strength and fracture toughness may be achieved in such composites by a more careful selection of matrix composition and heat treatment and has been reported in literature (England and Hall 1986, Manoharan and Lewandowski 1990) and by exercising greater care during processing.

\subsection{Effect of microstructural parameters on fracture toughness}

An understanding of how microstructural parameters such as $V_{f}, D$ and $\lambda$ influence fracture toughness would be very helpful in the proper selection of a composite for a particular application. Geometric consideration requires that the three microstructural variables be related. There are several expressions relating to $V_{f}, D$ and $\lambda$ available in literature (LeRoy et al 1981; Kelly 1973), the most widely used being

$$
\lambda=\left(\pi D^{2} / 6 V_{f}\right)^{1 / 2} .
$$

Thus if one can relate fracture toughness to interparticle spacing, the effect of volume fraction and particulate size, which can be controlled while processing; can also be determined using equation (1).

The trends in $K_{\mathrm{IC}}$ values with $\lambda$, together with the fractographic observations in aluminium alloy-alumina composite system, suggest that the fracture toughness is limited by particle spacing in a manner first suggested by Rice and Johnson (1969). According to their model all particles are considered to crack or decohere ahead of the major crack tip at a small local strain value. The region of intense plastic flow is limited to a volume of width $\lambda$ as illustrated in figure 3 . This would give a value for the energy release rate

$$
J_{1 \mathrm{C}}=\sigma_{f} \lambda
$$

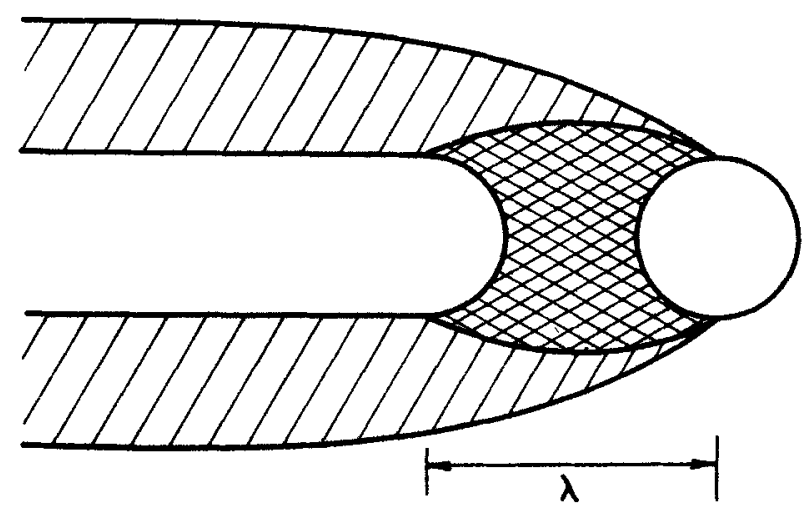

ZI PLASTICALLY DEFORMED REgION

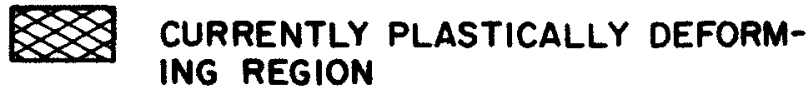

Figure 3. Region of intense plastic flow. 
where $\sigma_{f}$ is the flow stress and would imply that $J_{1 \mathrm{C}}$ would increase monotonically with $\lambda$. In order to test this surmise, data for $K_{\text {IC }}$ were converted to $J_{I C}$ values by the relation

$$
J_{\mathrm{IC}}=\left(K_{\mathrm{IC}}^{2} / E\right)\left[1-v^{2}\right]
$$

If the data were to fit the Rice-Johnson relation $J_{\mathrm{IC}} / \sigma_{f}$ should scale linearly with $\lambda$

$$
J_{\mathrm{Ic}} / \sigma_{f}=\lambda \text {. }
$$

A plot of this line is presented in figure 4 along with the experimental values of $J_{\mathrm{IC}} / \sigma_{f}$. As shown in the plot the data lie on or near the Rice-Johnson line for all cases where stable crack extension occurred, supporting the model. For the largest value of $\lambda$ for each alloy, corresponding to the largest particulate size, there was very little stable crack growth and $J_{I C} / \sigma_{f}$ values fell well below the expected trend.

For the cases of unstable crack growth, one would expect a behaviour analogous to that discussed by Evans (1983) for steels tested below the ductile-brittle transition temperatures. The initial crack begins to blunt and the stress is increased ahead of the crack because of plastic flow and because of hydrostatic stress elevation. A particle in the deformed region cracks and if the local energy release rate is sufficient, runs back to the main crack and triggers unstable crack growth. Statistically, the most likely particle to crack is unlikely to be at the maximum stress position, so the maximum stress, influencing the propagation of the microcrack back to the main crack, would tend to exceed the local stress by some small factor, leading to further plastic flow, work hardening and stress elevation prior to crack. Together, these factors would contribute to a local expected $K_{\text {IC }}$ value for the propagation of the microcracked particle into the matrix of $\sim 10$ $\sigma_{f} \sqrt{D}$, where $\sigma_{f}$ is the fracture stress. The value of $10 \sigma_{f} \sqrt{D}$ for the 2024-0 alloy with $D=50 \mu \mathrm{m}$ and $f=0.20$ is $13.7 \mathrm{MPa} \sqrt{\mathrm{m}}$, while that for the $2014-0$ alloy with

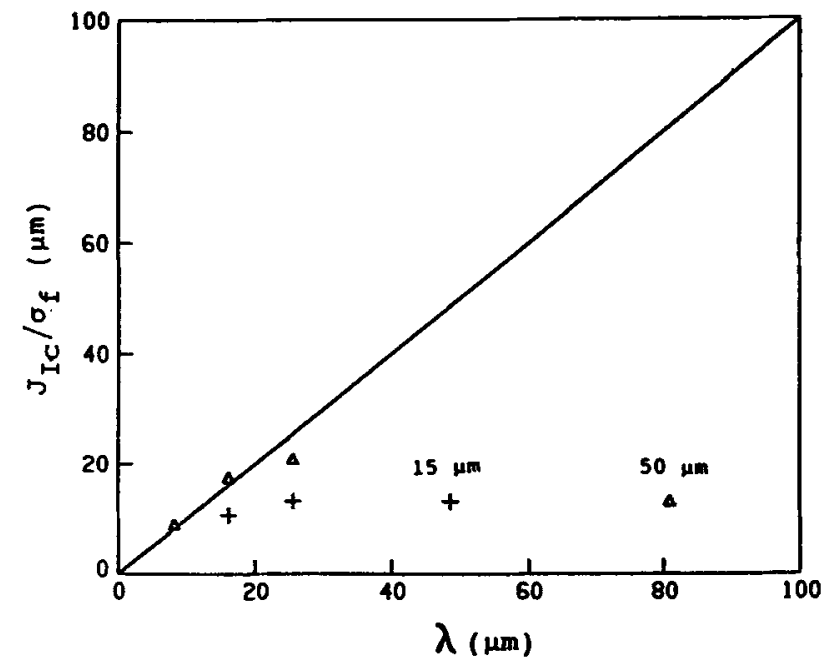

Figure 4. $J_{\mathrm{IC}} / \sigma_{f}$ versus interparticle spacing. Triangles for $2024 \mathrm{Al}$ and crosses for 2014 Al matrix composites. 
$D=15 \mathrm{~mm}$ and $f=0.05$ in $9.8 \mathrm{MPa} \sqrt{\mathrm{m}}$. It can be seen that these values agree fairly well with the experimentally measured toughness for these composites.

Thus, based on the above observations, it is evident that to obtain high fracture toughness, a large particle spacing is desirable. This could be achieved by either decreasing the volume fraction or increasing the particulate size provided the particle size does not exceed a critical value. The critical particle size corresponds to that for unstable propagation of a microcrack into the matrix.

\section{Conclusions}

Although particulate-reinforced metal-matrix composites exhibit limited macroscopic ductility, fracture in such composites occurs by the ductile mechanism of void nucleation, growth and linkage. The fracture toughness in such composites increases with particle spacing provided that the particle size is less than a critical value. This critical value corresponds to that for unstable propagation of a microcrack into the matrix.

\section{Acknowledgement}

The first author would like to acknowledge Shri S L N Acharyalu, Director, DMRL, Hyderabad for his permission to publish this work.

\section{References}

ASTM Annual Book of Standards 1987 E-399 p 680

Crowe C R and Gray R A 1984 in Failure mechanisms in high performance materials, Proc. 39th meeting of high performance Group, Gaithesberg, $\mathrm{p} 157$

England J and Hall I W 1986 Scr. Metall. 20697

Evans A G 1983 Metall. Trans. A14 1349

Hosking M F, Folgar-Portillo F, Wunderlin R and Mehrabian R 1982 J. Mater. Sci. 1747

Kelly P M 1973 Int. Met. Rev. 1831

LeRoy G, Embury J D, Edwards G and Ashby M F 1981 Acta Metall. 291509

Levi C G, Abbaschian G J and Mehrabian R 1978 Metall. Trans. A9 697

Manoharan M and Lewandowski J J 1990 Acta Metall. 20697

Nutt S R and Duva J M 1986 Scr. Metall. 201055

Quigley B F, Abbaschian G J, Wunderlin R and Mehrabian R 1982 Metall. Trans. A13 93

Rice J R and Johnson M A 1969 in lnelastic behaviour of solids (eds) M F Kanninen, W G Addler, A R Rosenfield and R I Jaffee (New York: McGraw-Hill) p 641

You C P, Thompson A W and Bernstein I M 1987 Scr. Metall. 21181 